\title{
Giardia-specific cellular immune responses in post-giardiasis chronic fatigue syndrome

Kurt Hanevik ${ }^{1,2^{*}} \mathbb{D}$, Einar Kristoffersen ${ }^{1,3}$, Kristine Mørch $^{1,2}$, Kristin Paulsen Rye ${ }^{1}$, Steinar Sørnes ${ }^{1}$, Staffan Svärd ${ }^{4}$, Øystein Bruserud ${ }^{1}$ and Nina Langeland ${ }^{1,2}$

\begin{abstract}
Background: The role of pathogen specific cellular immune responses against the eliciting pathogen in development of post-infectious chronic fatigue syndrome (PI-CFS) is not known and such studies are difficult to perform. The aim of this study was to evaluate specific anti-Giardia cellular immunity in cases that developed CFS after Giardia infection compared to cases that recovered well. Patients reporting chronic fatigue in a questionnaire study three years after a Giardia outbreak were clinically evaluated five years after the outbreak and grouped according to Fukuda criteria for CFS and idiopathic chronic fatigue. Giardia specific immune responses were evaluated in 39 of these patients by proliferation assay, T cell activation and cytokine release analysis. 20 Giardia exposed non-fatigued individuals and 10 healthy unexposed individuals were recruited as controls.

Results: Patients were clinically classified into CFS ( $n=15)$, idiopathic chronic fatigue $(n=5)$, fatigue from other causes $(n=9)$ and recovered from fatigue $(n=10)$. There were statistically significant antigen specific differences between these Giardia exposed groups and unexposed controls. However, we did not find differences between the Giardia exposed fatigue classification groups with regard to CD4 T cell activation, proliferation or cytokine levels in 6 days cultured PBMCs. Interestingly, SCD40L was increased in patients with PI-CFS and other persons with fatigue after Giardia infection compared to the non-fatigued group, and correlated well with fatigue levels at the time of sampling.
\end{abstract}

Conclusion: Our data show antigen specific cellular immune responses in the groups previously exposed to Giardia and increased SCD40L in fatigued patients.

Keywords: Giardia, T cell, Chronic fatigue syndrome, Antigen-specific, Immune response, sCD40L

\section{Background}

The causes and underlying mechanisms for development of chronic fatigue syndrome (CFS) remain unresolved. In some cases the condition is elicited by an infection, with mononucleosis due to Epstein Barr infection (EBV) being the most well-known [1]. However, it is also described to occur following a number of other infections [1]. When the onset of CFS is associated with an acute infection, it can be termed post-infectious (PI) and many researchers have focused on measures of the immune system in the quest to understand mechanisms and identify biomarkers [2-6].

\footnotetext{
* Correspondence: kurt.hanevik@med.uib.no

1 Department of Clinical Science, Lab-building 8.floor, University of Bergen,

N-5021 Bergen, Norway

${ }^{2}$ Center for Tropical Infectious Diseases, Haukeland University Hospital,

Bergen, Norway

Full list of author information is available at the end of the article
}

It is likely that the nature of the host reaction to the specific eliciting pathogens is implicated in development of PI-CFS. This is inherently difficult to study, as patients often present at a late stage where it is difficult to ascertain the specific eliciting pathogen and it is challenging to gather enough patients of a specific etiology to perform such studies.

An opportunity to investigate potential differences in the magnitude or quality of host responses towards the eliciting pathogen arose when a fraction of Giardia assemblage B infected persons developed post-infectious chronic fatigue (CF) after a large waterborne outbreak in Bergen, Norway in 2004 [7]. Most of these individuals also had co-morbid functional gastrointestinal disorders (FGID) elicited by the Giardia infection. Post-giardiasis chronic fatigue had not previously been described in the literature. It was the clinical follow-up of referred patients with persisting symptoms after successful 
Giardia treatment that informed the choice of questionnaires which were sent to all laboratory-confirmed cases two years after the outbreak [8], and at three years when we also included a control group [9]. Severity of the primary Giardia illness was a risk factor for developing both FGID and CF [10]. It became clear that chronic fatigue symptoms were four times more prevalent in the Giardia exposed group compared to controls [9]. Five years after the outbreak, PI-CFS was found in $42 \%(22 / 53)$ among patients who had reported chronic fatigue in the questionnaire three year after the outbreak [11].

In the present study we aimed to evaluate if Giardia specific immune responses such as proliferative capacity, CD4 T cell activation and cytokine profiles, were associated with development of CFS in this group of carefully clinically characterized persons. Responses were compared with a Giardia exposed group without fatigue, and with Giardia-naïve controls, in order to allow interpretation of the data with respect to Giardia exposure and specificity of the responses.

\section{Methods}

\section{Study populations}

Participants were recruited based on responses to a questionnaire mailed three years (in 2007) after the outbreak to all persons with laboratory confirmed giardiasis during the outbreak [9]. Patients who reported chronic fatigue in this questionnaire were invited to participate in a thorough clinical evaluation and screening two years later (in 2009). Fifty-three individuals agreed to participate, and went through a clinical evaluation by specialists in internal medicine, psychiatry and neurology. They were evaluated for CFS or idiopathic chronic fatigue (ICF) according to the 1994 Fukuda criteria [12]. Those fulfilling the criteria, and had an onset of symptoms related to the Giardia infection, were categorized as PI-CSF or PI-ICF. Patients with sleep apnea syndrome, significant depression or anxiety disorders that could plausibly explain their fatigue were termed "fatigue other cause". Individuals who had recovered well from the fatigue condition they had reported in the questionnaire two years previously were termed "fatigue recovered". Five patients were excluded from this study after clinical evaluation (Fig. 1).

Two control groups were recruited; 22 individuals with normal fatigue score $(=11)$ in the 2007 questionnaire (exposed, no-PI-fatigue group), and 10 healthy individuals not affected by the outbreak and without particular fatigue or abdominal symptoms (unexposed healthy controls) (Fig. 1). All participants were HIV negative and were not taking immunomodulatory medications or antibiotics.

\section{Sampling and questionnaires}

Participants were screened with a battery of routine blood tests and a magnetic resonance imaging (MRI)

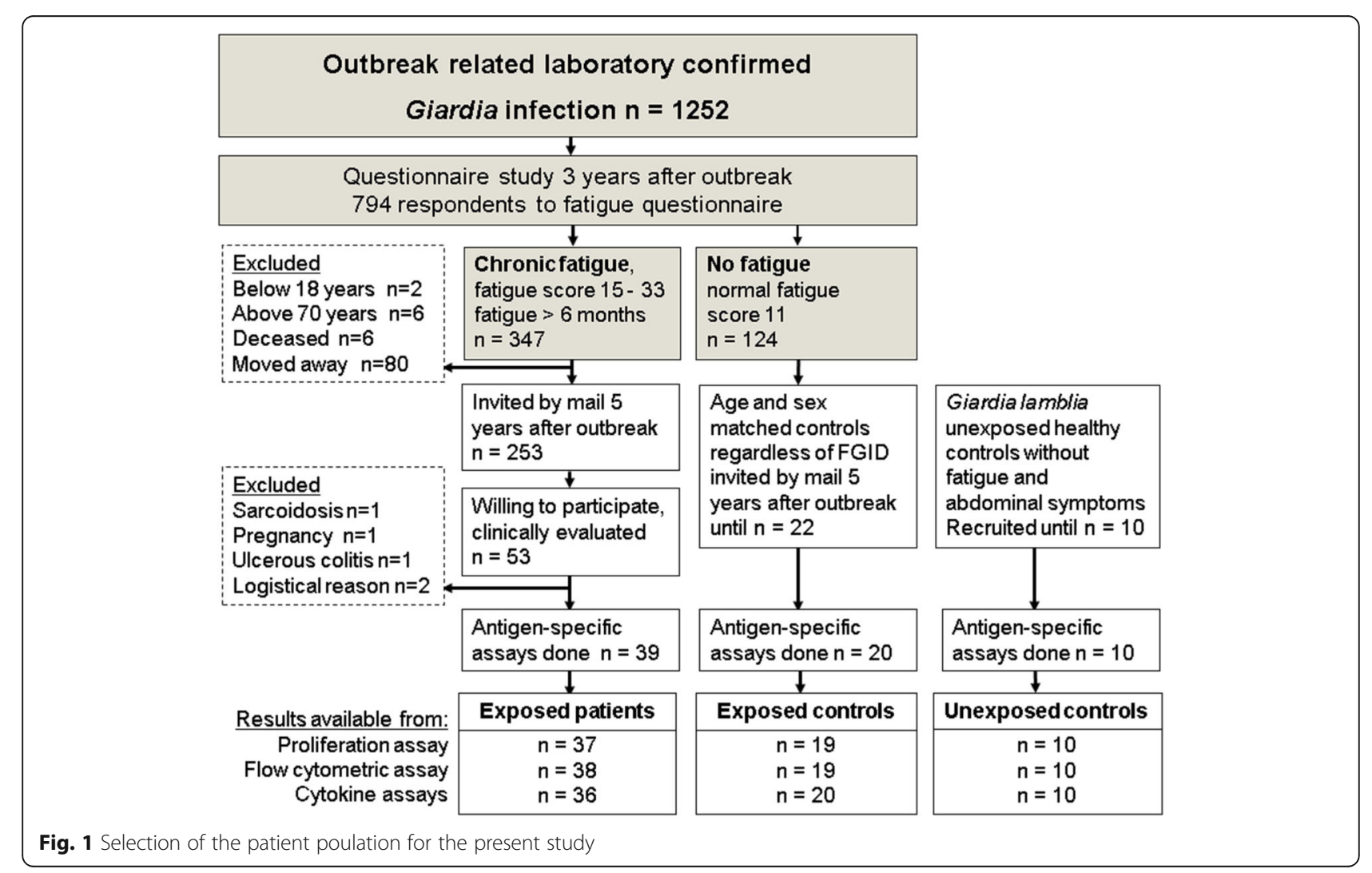


brain scan. Blood samples were taken between 08 am and 09 am after overnight fast and analyzed in parallel during the same period. Immunophenotyping results from these investigations have been reported previously [13]. Fecal samples were obtained and screened with microscopic examination and Giardia 18S PCR [14] of feces to rule out chronic giardiasis.

A total of 69 of the study participants underwent clinical characterization and were subject to one or more of the Giardia-specific immune response analyses presented in this paper. Some assays could not be done in all patients due to limited cell numbers (Fig. 1). Sampling and assays were stratified across groups and samples were blinded to laboratory personnel to avoid analytical bias. The severity of fatigue at the time of sampling was evaluated in all participants by the Fatigue Questionnaire [15], a validated set of 11 questions addressing different aspects of fatigue. Comorbid abdominal symptoms were recorded by the commonly used Rome II questionnaire [16].

\section{Antigens}

The Giardia antigens used in this study were made from culturing Giardia assemblage A strain WB-C6 (ATCC 50803) and assemblage B strain GS/M (ATCC 50581) in Diamond's TYI-S-33 medium supplemented with bile as described previously[17]. Trophozoites were washed in PBS, treeze-thawed, then sonicated for $1 \mathrm{~min}$ at $20 \mathrm{~W}$. After sentrifugation at $13000 \mathrm{x} \mathrm{g}$, the supernatant containing soluble Giardia proteins was removed, and protein content was measured by the BCA protein assay kit (Pierce). Pilot testing showed that $10 \mathrm{ug} / \mathrm{mL}$ of this mixed soluble Giardia antigens resulted in robust $\mathrm{T}$ cell responses and little background stimulation.

For the proliferation assay also a sterile filtered Candida albicans protein extract (403 skin prick test [Allergopharma]; $10000 \mathrm{BU} / \mathrm{mL}$ ), were added as an exploratory antigen and anti-CD3 + anti-CD28 as a control of $\mathrm{T}$ cell activation. Positive antigen controls were tuberculin purified protein derivate (PPD) (Statens Serum Institut) and Salmonella typhi LPS in all assays. Several concentrations were tested in pilot studies of all stimulation antigens and positive controls to optimize the assay.

\section{PBMC acquisition and antigen-specifc immunity assays}

Peripheral blood mononuclear cells (PBMC) were isolated from BD Vacutainer Na-citrate CPT tubes (BD, Franklin Lakes, NJ, USA) by density gradient separation. After harvesting, the PBMC were washed twice in PBS and were cultured in the presence or absence of investigational or control antigens at $37{ }^{\circ} \mathrm{C}$ in a humidified atmosphere of $5 \% \mathrm{CO}_{2}$ for six days in X-vivo 15 serumfree culture medium supplemented with L-glutamin, gentamicin, and phenol red (BioWhittaker).Proliferative responses were measured in triplicates of stimulated cultured cells by adding ${ }^{3} \mathrm{H}$-thymidine (Amersham International) after five days, and harvesting $18 \mathrm{~h}$ later. Incorporated radioactivity was analysed by liquid scintillation counting in a $\beta$-counter. Proliferation in stimulated and unstimulated cultures was determined as median counts per minute $(\mathrm{cpm})$ of each triplicate.

Activation of $\mathrm{T}$ cells was evaluated after six days in culture. $100 \mu \mathrm{L}$ supernatants were carefully harvested from wells of unstimulated and stimulated PBMCs and frozen at $-80{ }^{\circ} \mathrm{C}$ for later cytokine analysis. The cultured cells were then analysed by flow cytometric measurement of activated $\mathrm{T}$ cell subsets as published previously [17]. Briefly, after washing with PBS, the cultured cell suspensions $(50 \mu \mathrm{L})$ were stained for $30 \mathrm{~min}$ in the dark with combination of 5 fluorescent dyes: CD3-ECD (Beckman Coulter), CD8a-FITC and CD4-PerCP/Cy5.5 and the activation markers CD26-PE and CD25-PE/Cy7 (BioLegend). After staining, cells were washed once, resuspended in PBS-paraformaldehyde solution (1\%) and analyzed the same day using a Beckman Coulter Cytomics FC 500 MPL flow cytometer. In a typical acquisition $7 \times 10^{4} \mathrm{lym}$ phocytes (min $2.3 \times 10^{4}, \max 1.7 \times 10^{5}$ ) were collected. The collected data were analyzed with FlowJo 7.6 software (Tree Star Inc, Ashland, OR, USA). Background responses in unstimulated cultures were adjusted for by subtracting these from responses in stimulated cultures.

Supernatants were kept frozen until analysis in three Bio-Plex assays (Bio-Rad Laboratories Inc., Hercules, CA, USA) for IFN- $\gamma$, TNF- $\alpha$, IL-1 $\beta$, IL-2, IL-4, IL-6, IL9, IL-10, IL-13, IL-17A, IL-22, soluble (s) sCD40L, macrophage inflammatory protein 1 alpha (MIP-1 $\alpha$ ), MIP-1 $\beta$, TGF $\beta 1$, TGF $\beta 2$, TGF $\beta 3$ and granulocyte macrophage colony-stimulation factor (GM-CSF) according to the manufacturer's instructions. The cytokines TGF $\beta 1$, TGF $\beta 2$, TGF $\beta 3$ were analyzed in unstimulated and Giardia antigen stimulated cultures only. Observed concentrations $(\mathrm{pg} / \mathrm{ml})$ within the standard range were used for analysis. Values above the limit of quantitation were set to the highest value in the standard range, and values below this range were set to zero. For analytes where less than $50 \%$ of values were within range, further analyses were not done.

For both flow cytometric and cytokine assays, background responses in unstimulated cultures were subtracted from those in stimulated cultures for each participant. In some cases this gave negative values in the cytokine assay which were kept in the statistical analyses and interpreted as stimulant-induced decrease in production or increase in consumption of the relevant analyte.

\section{Statistical analysis}

Unless otherwise stated the data are presented as median (standard deviation (SD)). Chi-squared tests 
were used for categorical comparisons between groups. Linear regression analysis was used for correlation between response parameters as well as fatigue scores and $\mathrm{sCD} 40 \mathrm{~L}$ data. Comparison of $\mathrm{T}$ cell activation, proliferation and cytokine data between exposed and unexposed groups was done using the Mann Whitney $U$ test. The significance level was set at $p<0.05$. To reduce false positive findings due to multiple comparisons within the exposed groups, we used the Kruskal-Wallis test across all exposed groups first, and further testing between the no PI-fatigue and PI-CFS/PI-ICF groups with Mann Whitney $U$ test was only performed for variables with a $\mathrm{p}$ value less than 0.05. IBM SPSS Statistics version 23 (IBM Corp, Armonk, USA) was used for statistical analysis.

\section{Results}

\section{Patient characteristics}

Patients and controls were grouped according to their clinical condition at the time of sampling. Data from 39 patients (median age 40.9 years (11.2) range 19-62, females 74\%), 20 exposed controls (median age 39.5 (9.3) range 27-66, females 75\%) and 10 unexposed controls (median age 43.3 (14.3) range 22-63, females 70\%) were analyzed in this study. There were no significant differences in age $(p=0.06)$ or sex distribution $(p=0.61)$. Fatigued patients were categorized according to their clinical categories for analyses of antigen specific immune responses (Table 1). ICF and CFS were combined in the further analyses as they were seen as a common phenotype with difference only in severity of symptoms. The fatigue scores generally reflected the categorization obtained by careful clinical evaluation with the cases of CSF scoring higher than the ICF and fatigue by other cause groups. The patients who had recovered well still

\begin{tabular}{|c|c|c|c|c|}
\hline & $\begin{array}{l}\text { Age, median } \\
\text { (SD) }\end{array}$ & $\begin{array}{l}\text { Females, } \\
n(\%)\end{array}$ & $\begin{array}{l}\text { Fatigue score } \\
\text { in 2009, } \\
\text { median (SD) }\end{array}$ & $\begin{array}{l}\text { Total } \\
\text { participants, }\end{array}$ \\
\hline \multicolumn{5}{|l|}{ Giardia exposed } \\
\hline $\begin{array}{l}\text { No Pl-fatigue } \\
\text { controls }\end{array}$ & $39.5(9.3)$ & $15(75)$ & $11(1.3)$ & 20 \\
\hline PI-CFS & $47.0(8.6)$ & $11(73)$ & $22.0(5.3)$ & 15 \\
\hline $\mathrm{PI}-\mathrm{ICF}$ & $35.0(8.9)$ & $4(80)$ & $20.0(3.1)$ & 5 \\
\hline $\begin{array}{l}\text { Fatigue other } \\
\text { cause }\end{array}$ & $51.0(15.6)$ & $9(100)$ & $18.0(5.1)$ & 9 \\
\hline $\begin{array}{l}\text { Recovered } \\
\text { from fatigue }\end{array}$ & $31.0(5.8)$ & $5(50)$ & $17.0(3.3)$ & 10 \\
\hline \multicolumn{5}{|c|}{ Giardia unexposed } \\
\hline $\begin{array}{l}\text { Healthy } \\
\text { controls }\end{array}$ & $39(11.1)$ & $7(70)$ & $11(2.1)$ & 10 \\
\hline
\end{tabular}

Abbreviations: $P$ I post-infectious, CFS chronic fatigue syndrome, ICF idiopathic chronic fatigue had a modestly elevated fatigue score compared to recruited exposed and unexposed controls.

\section{Giardia-induced proliferation of immunocompetent cells}

PMBC proliferated well in response to all stimuli included in this assay. A marked memory response was seen in the Giardia exposed groups that showed significantly stronger proliferation in response to the Giardia lysates compared to the unexposed group (Table 2). However, the proliferative responses to Giardia antigens did not differ significantly between the fatigue categories within the exposed group (Table 2). For the other specific antigen controls we found neither a difference with regard to previous exposure to Giardia, nor according to fatigue sequels. There was a trend towards decreased proliferation induced by the strong $\mathrm{T}$ cells activator anti-CD3antiCD28 among the fatigued groups compared to the no fatigued controls, but this did not attain significance (Table 2).

\section{Giardia-induced $T$ cell expression of activation markers}

Levels of activated CD4 T cells expressing CD25 and CD26 were significantly elevated in Giardia exposed groups compared to unexposed patients when stimulated with both Giardia assemblage A and assemblage B lysates (Table 3). The PPD and LPS control antigens induced similar levels of activated CD4 T cells in both exposed and unexposed groups. None of these stimuli induced differences between the exposed participants with or without fatigue sequels. The flow cytometric responses correlated well with proliferation responses to the same antigens with $p<0.001$ for assemblage A stimulation and $p=0.001$ for assemblage $\mathrm{B}$ stimulated cultures.

\section{Giardia-induced release of soluble mediators}

In Table 4 the results of cytokines and sCD40L are given for levels of an array of cytokines and sCD40L in supernatants of PBMC stimulated for six days with Giardia assemblage B lysate. There were significant differences for most of these, except IL-4, IL-2, TGF $\beta 2$ and TGF $\beta 3$ between the Giardia exposed and unexposed participants. The same pattern was seen, but with weaker differences in responses to Giardia assemblage A. For PPD there were smaller, but significant differences only for IFNY and sCD40L between exposed and unexposed groups, while for LPS stimulated supernatants no difference was found (Additional file 1: Table S1).

In the analysis of Giardia antigen induced differences in cytokine profiles with regard to fatigue outcome we found only SCD40L to be significantly different within exposed groups (KruskalWallis $p=0.03$ ) and the PICFS/PI-ICF groups having significantly elevated levels of sCD40L compared to the no PI-fatigue groups (Table 4). Also a significant difference was found when comparing 
Table 2 Immune responses against Giardia and control antigens as measured by ${ }^{3} \mathrm{H}$-thymidine proliferation assay

\begin{tabular}{|c|c|c|c|c|c|c|c|}
\hline \multirow[b]{2}{*}{ Stimulation agent } & \multicolumn{4}{|l|}{ Exposed } & \multirow{2}{*}{$\begin{array}{l}\text { Unexposed } \\
\text { Healthy controls } \\
(n=10)\end{array}$} & \multicolumn{2}{|l|}{$p$-values } \\
\hline & $\begin{array}{l}\text { No Pl-fatigue } \\
\text { controls }(n=19)\end{array}$ & $\begin{array}{l}\text { PI-CFS \& } \\
\text { ICF }(n=19)\end{array}$ & $\begin{array}{l}\text { Fatigue other } \\
\text { cause }(n=9)\end{array}$ & $\begin{array}{l}\text { Recovered from } \\
\text { fatigue }(n=9)\end{array}$ & & $\begin{array}{l}\text { Exposed } n=56) \text { vs } \\
\text { unexposed }(n=10)\end{array}$ & $\begin{array}{l}\text { No Pl-fatigue controls } \\
(n=19) \text { vs PI-CFS/ICF } \\
(n=19)\end{array}$ \\
\hline Giardia ass A $10 \mu \mathrm{g} / \mathrm{ml}$ & $12.8(13.0)$ & $15.3(19.9)$ & $20.3(10.9)$ & $15.1(65.0)$ & $3.5(6.2)$ & 0.001 & $n s^{*}$ \\
\hline Giardia ass B $10 \mu \mathrm{g} / \mathrm{ml}$ & $12.2(13.9)$ & $13.3(15.3)$ & $23.3(13.4)$ & $15.3(39.0)$ & $3.5(4.7)$ & $<0.001$ & $n s^{*}$ \\
\hline $\begin{array}{l}\text { Tuberculin (PPD) } 10 \\
\mu \mathrm{g} / \mathrm{ml}\end{array}$ & $26.3(34.1)$ & $34.0(47.5)$ & $54.9(84.5)$ & $42.5(23.2)$ & $27.7(27.0)$ & ns & $n s^{*}$ \\
\hline LP S Stypi $1 \mu \mathrm{g} / \mathrm{ml}$ & $21.5(18.6)$ & $14.4(13.2)$ & $38.2(34.3)$ & $21.9(19.5)$ & $17.7(10.5)$ & ns & $n s^{*}$ \\
\hline C albicans $10 \mu \mathrm{g} / \mathrm{ml}$ & $7.0(9.1)$ & $5.8(11.9)$ & $10.0(32.0)$ & $14.6(6.0)$ & $11.0(9.4)$ & ns & $\mathrm{ns}^{*}$ \\
\hline $\mathrm{aCD} 3 \mathrm{aCD} 28$ (pos ctr) & $70.6(35.4)$ & $51.4(33.0)$ & $51.8(44.1)$ & $51.8(63.9)$ & $60.1(39.8)$ & ns & $n s^{*}$ \\
\hline
\end{tabular}

*KruskalWallis test across all exposed groups was not significant (below $p=0.05$ ). ns = not significant

Proliferation responses are expressed as median stimulation indices (counts per minute(cpm) in stimulated triplicate cultures divided by cpm in unstimulated triplicate cultures) followed by standard deviation

the no-PI-fatigue group with the PI-CFS group $(n=14)$ alone, and with the fatigue other cause group $(p=0.038)$, but not with the recovered group. Interestingly, sCD40L levels in supernatants correlated well with fatigue scores $(p=0.001)$, shown in Fig. 2.

The antigen-specific immune responses were also explored with regard to co-morbidity with functional gastrointestinal disorders, but significant correlations were not found (data not shown).

\section{Discussion}

The data presented in this study confirm previous finding of long term $\mathrm{T}$ cell memory responses towards Giardia [17], and bring new data on cytokines profiles elicited in this response. However, in the present study, performed in a well-defined group of patients with clinically observed post-infectious FGID and CFS five years after a common eliciting infection, we did not identify any differences in the antigen-specific cellular immunity against the culprit infectious agent, in this case G. lamblia. The higher levels of sCD40L in supernatants in Giardia stimulated PBMCs from persons with PI-CFS correlated well with fatigue scores, but could be unspecific for PI-CFS as it was also found in persons reporting fatigue that could be explained by other conditions. An alternative explanation could be that also these could have a component of Giardia induced fatigue, but they did not fulfil the Fukuda criteria due to their other illness. As such, further investigation is warranted to evaluate whether sCD40L might be a marker of fatigue in general or a marker for PI-CFS. Alternatively, this may be an effect related to Giardia exposure in all the fatigued patients. Since we did not include a control group of fatigued patients without Giardia exposure, we cannot conclude firmly on these options.

The present study thus underlines the need to include patient control groups where fatigue is a common symptom in all studies looking for biomarkers of CFS. Our study design, which included exposed groups with fatigue, but not fulfilling the criteria for CFS/ICF allowed for a more cautious interpretation. A previous study has found that an increase in serum sCD40L eight hours after exertion correlated with increases in physical fatigue $48 \mathrm{~h}$ post-exertion [18]. Our data support that CD40L, a co-stimulatory molecule which is found on a variety of cells and promotes B cell maturation, could be a marker of fatigue. Another study has suggested that sCD40L can increase blood brain permeability in vivo,

Table 3 Immune responses against Giardia and control antigens as measured by the percentage of CD25CD26 positive CD4 T cells by flow-cytometry

\begin{tabular}{|c|c|c|c|c|c|c|c|}
\hline \multirow[b]{2}{*}{ Stimulation agent } & \multicolumn{4}{|l|}{ Exposed } & \multirow{2}{*}{$\begin{array}{l}\text { Unexposed } \\
\text { Healthy controls } \\
(n=10)\end{array}$} & \multicolumn{2}{|l|}{$p$-values } \\
\hline & $\begin{array}{l}\text { No Pl-fatigue } \\
\text { controls }(n=19)\end{array}$ & $\begin{array}{l}\text { PI-CFS \& ICF } \\
(n=18)\end{array}$ & $\begin{array}{l}\text { Fatigue other } \\
\text { cause }(n=9)\end{array}$ & $\begin{array}{l}\text { Recovered from } \\
\text { fatigue }(n=10)\end{array}$ & & $\begin{array}{l}\text { Exposed }(n=56) \\
\text { vs unexposed } \\
(n=10)\end{array}$ & $\begin{array}{l}\text { No Pl-fatigue controls } \\
(n=19) \text { vs PI-CFS/ICF } \\
(n=19)\end{array}$ \\
\hline Giardia ass A $10 \mu \mathrm{g} / \mathrm{ml}$ & $8.6(5.8)$ & $10.3(7.7)$ & $8.8(5.0)$ & $12.4(8.1)$ & $1.8(3.9)$ & 0.001 & $n s^{*}$ \\
\hline Giardia ass B $10 \mu \mathrm{g} / \mathrm{ml}$ & $3.1(2.2)$ & $4.3(7.3)$ & $3.7(3.9)$ & $7.9(5.7)$ & $1.9(1.6)$ & 0.009 & $n s^{*}$ \\
\hline Tuberculin (PPD) $10 \mu \mathrm{g} / \mathrm{ml}$ & $6.6(5.4)$ & $11.3(11.1)$ & $9.2(11.4)$ & $13.6(5.2)$ & $10.0(13.6)$ & ns & $n s^{*}$ \\
\hline LPS S. typi $1 \mu \mathrm{g} / \mathrm{ml}$ & $5.2(5.5)$ & $5.2(9.6)$ & $4.5(2.5)$ & $5.1(2.9)$ & $3.0(14.6)$ & ns & $n s^{*}$ \\
\hline
\end{tabular}

The values are percentages of activated CD4 T cells out of all CD4 T cells in stimulated cultures subtracted by the percentage of activated CD4 T cells in unstimulated culture

*KruskalWallis test across all exposed groups was not significant (below $p=0.05$ ). ns $=$ not significant 
Table 4 Analyses of cytokines and sCD40L in supernatants of PBMC cultured for six days after stimulation with Giardia assemblage B lysate in persons exposed to this pathogen in the Bergen 2004 outbreak with or without fatigue sequels, and in unexposed controls

\begin{tabular}{|c|c|c|c|c|c|c|c|}
\hline \multirow[b]{2}{*}{ Analyte } & \multicolumn{4}{|l|}{ Exposed } & \multirow{2}{*}{$\begin{array}{l}\text { Unexposed } \\
\text { Healthy controls } \\
(n=10)\end{array}$} & \multicolumn{2}{|l|}{$p$-values } \\
\hline & $\begin{array}{l}\text { No Pl-fatigue controls } \\
(n=20)\end{array}$ & $\begin{array}{l}\text { PI-CFS \& ICF } \\
(n=19)\end{array}$ & $\begin{array}{l}\text { Fatigue other } \\
\text { cause }(n=8)\end{array}$ & $\begin{array}{l}\text { Fully recovered } \\
(n=9)\end{array}$ & & $\begin{array}{l}\text { Exposed }(n=56) \text { vs } \\
\text { unexposed }(n=10)\end{array}$ & $\begin{array}{l}\text { No Pl-fatigue controls } \\
(n=20) \text { vs PI-CFS/ICF } \\
(n=19)\end{array}$ \\
\hline $\mathrm{IL}-1 \mathrm{~b}$ & $8.4(63.5)$ & $23.7(211)$ & $10.0(37.0)$ & $37.3(207)$ & $0.8(8.8)$ & $<0.001$ & $\mathrm{~ns}^{*}$ \\
\hline $\mid \mathrm{L}-4$ & $4.1(6.6)$ & $4.9(4.8)$ & $-0.7(7.4)$ & 7.7 (5.6) & $4.0(29.4)$ & 0.838 & $n s^{*}$ \\
\hline IL-6 & 496 (8364) & 781 (18566) & 957 (659) & 741 (991) & $85.3(310)$ & $<0.001$ & $n s^{*}$ \\
\hline IL-10 & $19.7(23.3)$ & $25.2(354)$ & $22.7(13.2)$ & $25.1(5.9)$ & $7.1(25.3)$ & $<0.001$ & $n s^{*}$ \\
\hline IFNy & 1009 (3656) & $1627(4637)$ & 775 (2569) & 2577 (2322) & 31.6 (956) & $<0.001$ & $n s^{*}$ \\
\hline sCD40L & $7.5(25.0)$ & $35.6(59.0)$ & $26.6(27.3)$ & $19.5(53.5)$ & $0.0(43.2)$ & 0.003 & 0.005 \\
\hline TNFa & $192(407)$ & $346(713)$ & $213(990)$ & 395 (787) & $7.6(166)$ & $<0.001$ & $n s^{*}$ \\
\hline IL-2 & $5.9(9.3)$ & $7.1(8.1)$ & $15.7(15.1)$ & $6.1(8.9)$ & $4.7(4.6)$ & 0.107 & $n s^{*}$ \\
\hline IL-9 & 11.7 (39.7) & 23.5 (155) & $20.3(22.9)$ & $23.6(115)$ & $2.8(14.5)$ & 0.018 & $n s^{*}$ \\
\hline IL-13 & $230(203)$ & $262(212)$ & $248(371)$ & $441(272)$ & $72.8(100)$ & 0.002 & $n s^{*}$ \\
\hline $\mathrm{MIPa}$ & $51.1(657)$ & $112(645)$ & $252(427)$ & $692(540)$ & 15.5 (399) & 0.034 & $n s^{*}$ \\
\hline $\mathrm{MIPb}$ & 1691 (1856) & 2306 (1939) & 1754 (1618) & 2862 (4195) & $258(1765)$ & 0.034 & $n s^{*}$ \\
\hline TGFb1 & $-959(2759)$ & $-2083(2243)$ & $-1914(1869)$ & $-2749(3429)$ & $-3680(1438)$ & 0.033 & $n s^{*}$ \\
\hline TGFb2 & $-43.2(61.7)$ & $5.7(46.4)$ & $7.5(111)$ & $21.0(45.0)$ & $-34.7(61.1)$ & 0.132 & $n s^{*}$ \\
\hline TGFb3 & $4.7(23.0)$ & $-10.5(19.3)$ & $-7.2(8.3)$ & $-20.5(15.3)$ & $-10.3(43.0)$ & 0.869 & $n s^{*}$ \\
\hline
\end{tabular}

*KruskalWallis test across all exposed groups was not significant (below $p=0.05$ )

Values are $\mathrm{pg} / \mathrm{mL}$, median (SD) in stimulated cultures after subtracting measurements in unstimulated cultures. Values are given for analyte measurements that were of sufficient quality for further analysis

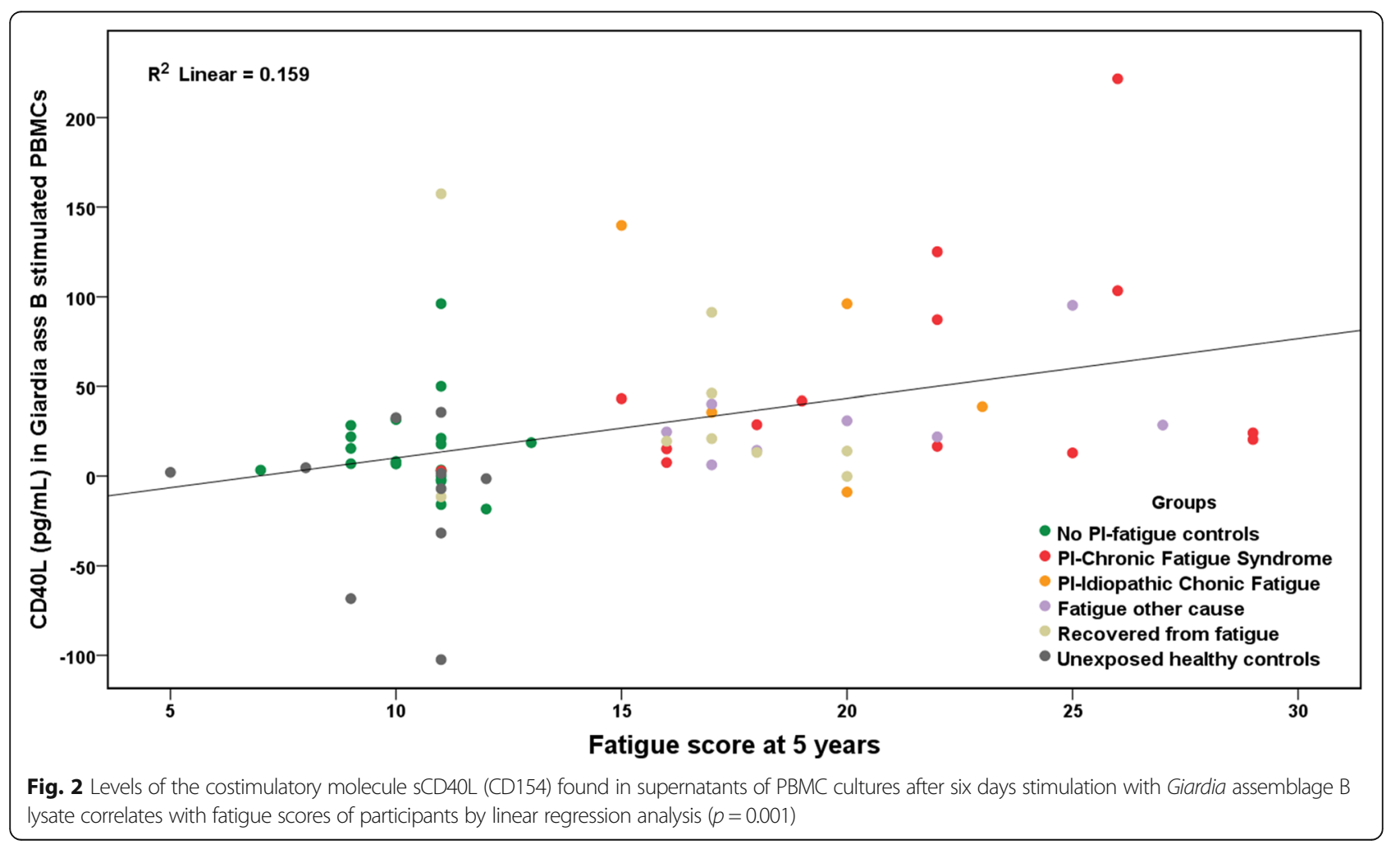


and this could be a mechanism deserving further research [19].

Few studies are available to compare our data with. In line with the present study an analysis of specific humoral immunity in PI-CFS after parvovirus B19 infection did not identify any pattern distinguishing this illness [20]. Epstein-Barr virus specific cellular immune responses have been investigated in a CFS patient group of uncharacterized etiology, finding lower levels of polyfunctional ebna-1 specific $T$ cells, whereas no differences in cytomegalovirus-responses were detected [21].

Curriu et al. found general cellular proliferative responses to be decreased in PBMCs from CFS patients [22], possibly due to increased number of regulatory $\mathrm{T}$ cells. We did observed a weaker proliferative response to strong $\mathrm{T}$ cell activation with anti-CD3/anti-CD28 stimulation in the CFS/ICF group, but these results were not statistically significant. Additionally, we also observed weaker, but non-significant, proliferative responses in the other exposed groups.

Our patient cohort offered a rare chance to study cellular immune responses to the eliciting pathogen. However, participants were recruited from a group of people who had a common exposure five years previously, and were therefore limited in number. We included those who were willing to participate, and had no chance to expand recruitment. From talking to individuals who did not wish to participate we learned that many of these experienced a substantial improvement in their condition between three and five years after the outbreak.

There was a large variation observed in measurements, causing large SDs. Some of this is likely due to the multiplicative effect of even small differences after culturing cells for six days.

The cytokine IL-17 which we have shown to play a role in human memory responses against Giardia infections [23] had high background levels in supernatants in the present study, leaving too few values measurable, and could not be analyzed.

Examination at an earlier time point where we would have been able to recruit more individuals still fulfilling the CFS criteria into the study could have increased the statistical power, and could possibly have resulted in stronger, more distinct immune responses.

\section{Conclusion}

While these data confirm previous finding of $\mathrm{T}$ cell memory responses towards Giardia and bring new data on cytokine profiles, they did not reveal a difference in the magnitude of Giardia-specific $\mathrm{T}$ cell responses with respect to post-giardiasis CFS. Neither were differences in the quality of these responses, as measured by cytokine profiles in supernatants above Giardia stimulated
PBMCs, found, except for sCD40L being elevated in the PI-CFS/ICF group as well as other exposed cases who experienced fatigue after the outbreak Giardia assemblage B infection.

\section{Additional file}

Additional file 1: Table S1. Cultured PBMC supernatant analysis. Analyses of cytokines and soluble CD40L in supernatants of PBMC cultured for 6 days stimulated with Giardia lysates. (PDF 72 kb)

\section{Abbreviations \\ ATCC: American type culture collection; CFS: Chronic fatigue syndrome; EBV: Epstein barr infection; FGID: Functional gastrointestinal disorder; HIV: Human immunodeficiency virus; ICF: Idiopathic chronic fatigue; IL: Interleukin; LPS: Lipopolysaccaride; PBMC: Peripheral blood mononuclear cells; PBS: Phosphate buffered saline; PCR: Polymerase chain reaction; PI: Post- infectious; PPD: Purified protein derivate; SCD40L: Soluble cluster of differentiation 40 ligand}

\section{Acknowledgements}

We want to thank the staff at the hospital clinical routine laboratory, the study participants and also Marita Wallevik, Knut-Arne Wensaas, Guri Rørtveit, Bjarte Stubhaug, Marit Tellevik, Christel Haanshuus, Geir Egil Eide, Halvor Næss, Ann Christin Rivenes, Jørn Eilert Bødtker and Harald Inge Nyland for their cooperation, advice and assistance in this project.

\section{Funding}

This work was supported by The Western Norway Regional Health Authority project number 911571 and the University of Bergen. Data were analyzed and evaluated independently by the authors, without any interference from the funding institution.

\section{Availability of data and materials}

There is a requirement in the consent form that the individual cannot be identified in the published data. The datasets generated and analyzed during the current study are therefore not publicly available due to a limited number of participants, which will be easily identifiable by few key variables. Data could be made available on reasonable request with permission from the Regional Committee for Ethics in Medical Research in Western Norway.

\section{Authors' contributions}

Laboratory work, data collection and analyses were done by KH, EKK, SSø and KPR. Giardia antigens were prepared and supplied by SSv. Clinical evaluation and classification of patients was done by KM. OB and KPR assisted in planning and cytokine analysis. NL supervised all parts of the study. All authors assisted in preparation of, and approved, the final manuscript.

\section{Competing interests}

K.H. has been a consultant for Lupin Pharmaceuticals Inc. The other authors declare that they have no competing interests.

\section{Consent to Publish}

Not applicable.

Ethics approval and consent to participate

Written consent was obtained from the participants. The study was approved by the Regional Committee for Ethics in Medical Research in Western Norway (152.08).

\section{Author details}

'Department of Clinical Science, Lab-building 8.floor, University of Bergen, N-5021 Bergen, Norway. ${ }^{2}$ Center for Tropical Infectious Diseases, Haukeland University Hospital, Bergen, Norway. ${ }^{3}$ Department of immunology and transfusion medicine, Haukeland University Hospital, Bergen, Norway. ${ }^{4}$ Department of Cell and Molecular biology, Uppsala University, Uppsala, Sweden. 
Received: 20 October 2016 Accepted: 23 January 2017

Published online: 28 January 2017

\section{References}

1. Hickie I, Davenport T, Wakefield D, Vollmer-Conna U, Cameron B, Vernon SD, Reeves WC, Lloyd A. Post-infective and chronic fatigue syndromes precipitated by viral and non-viral pathogens: prospective cohort study. BMJ. 2006;333(7568):575

2. Gow JW, Hagan S, Herzyk P, Cannon C, Behan PO, Chaudhuri A. A gene signature for post-infectious chronic fatigue syndrome. BMC Med Genomics. 2009;2:38.

3. Masuda A, Munemoto T, Yamanaka T, Takei M, Tei C. Psychosocial characteristics and immunological functions in patients with postinfectious chronic fatigue syndrome and noninfectious chronic fatigue syndrome. J Behav Med. 2002;25(5):477-85.

4. Devanur LD, Kerr JR. Chronic fatigue syndrome. J Clin Virol. 2006;37(3):139-50

5. Spiller R, Garsed K. Postinfectious irritable bowel syndrome. Gastroenterology. 2009;136(6):1979-88.

6. Hardcastle SL, Brenu EW, Johnston S, Nguyen T, Huth T, Ramos S, Staines D, Marshall-Gradisnik S. Longitudinal analysis of immune abnormalities in varying severities of chronic fatigue syndrome/myalgic encephalomyelitis patients. J Transl Med. 2015;13:299.

7. Nygard K, Schimmer B, Sobstad O, Walde AK, Tveit I, Langeland N, Hausken T, Aavitsland P. A large community outbreak of waterborne giardiasisdelayed detection in a non-endemic urban area. BMC Public Health. 2006;6(1):141.

8. Morch K, Hanevik K, Rortveit G, Wensaas KA, Langeland N. High rate of fatigue and abdominal symptoms 2 years after an outbreak of giardiasis. Trans R Soc Trop Med Hyg. 2009;103(5):530-2. doi: 10.1016/j.trstmh.2009.01. 010.

9. Wensaas KA, Langeland N, Hanevik K, Morch K, Eide GE, Rortveit G. Irritable bowel syndrome and chronic fatigue 3 years after acute giardiasis: historic cohort study. Gut. 2012;61(2):214-9.

10. Morch K, Hanevik K, Rortveit G, Wensaas KA, Eide GE, Hausken T, Langeland $\mathrm{N}$. Severity of giardia infection associated with post-infectious fatigue and abdominal symptoms two years after. BMC Infect Dis. 2009;9(1):206.

11. Morch K, Hanevik K, Rivenes AC, Bodtker JE, Naess H, Stubhaug B, Wensaas KA, Rortveit G, Eide GE, Hausken T, et al. Chronic fatigue syndrome 5 years after giardiasis: differential diagnoses, characteristics and natural course. BMC Gastroenterol. 2013;13:28.

12. Fukuda K, Straus SE, Hickie I, Sharpe MC, Dobbins JG, Komaroff A. The chronic fatigue syndrome: a comprehensive approach to its definition and study. International chronic fatigue syndrome study group. Ann Intern Med. 1994;121(12):953-9.

13. Hanevik K, Kristoffersen EK, Sornes S, Morch K, Naess H, Rivenes AC, Bodtker JE, Hausken T, Langeland N. Immunophenotyping in post-giardiasis functional gastrointestinal disease and chronic fatigue syndrome. BMC Infect Dis. 2012;12:258.

14. Verweij JJ, Blange RA, Templeton K, Schinkel J, Brienen EA, van Rooyen MA, van Lieshout L, Polderman AM. Simultaneous detection of entamoeba histolytica, giardia lamblia, and cryptosporidium parvum in fecal samples by using multiplex real-time PCR. J Clin Microbiol. 2004:42(3):1220-3.

15. Chalder T, Berelowitz G, Pawlikowska T, Watts L, Wessely S, Wright D, Wallace EP. Development of a fatigue scale. J Psychosom Res. 1993;37(2):147-53.

16. Drossman DA. The functional gastrointestinal disorders and the Rome II process. Gut. 1999;45 Suppl 2:॥1-5.

17. Hanevik K, Kristoffersen E, Svard S, Bruserud O, Ringqvist E, Sornes S, Langeland N. Human cellular immune response against giardia lamblia 5 years after acute giardiasis. J Infect Dis. 2011;204(11):1779-86.

18. White AT, Light AR, Hughen RW, Bateman L, Martins TB, Hill HR, Light KC. Severity of symptom flare after moderate exercise is linked to cytokine activity in chronic fatigue syndrome. Psychophysiology. 2010;47(4):615-24.

19. Davidson DC, Hirschman MP, Sun A, Singh MV, Kasischke K, Maggirwar SB. Excess soluble CD40L contributes to blood brain barrier permeability in vivo: implications for HIV-associated neurocognitive disorders. PLoS One. 2012;7(12):e51793.

20. Kerr JR, Bracewell J, Laing I, Mattey DL, Bernstein RM, Bruce IN, Tyrrell DA. Chronic fatigue syndrome and arthralgia following parvovirus B19 infection. J Rheumatol. 2002;29(3):595-602.
21. Loebel M, Strohschein K, Giannini C, Koelsch U, Bauer S, Doebis C, Thomas S, Unterwalder N, von Baehr V, Reinke P, et al. Deficient EBV-specific B- and T-cell response in patients with chronic fatigue syndrome. PLoS One. 2014;9(1):e85387.

22. Curriu M, Carrillo J, Massanella M, Rigau J, Alegre J, Puig J, Garcia-Quintana AM, Castro-Marrero J, Negredo E, Clotet B, et al. Screening NK-B- and T-cell phenotype and function in patients suffering from chronic fatigue syndrome. J Transl Med. 2013;11:68.

23. Saghaug CS, Sornes S, Peirasmaki D, Svard S, Langeland N, Hanevik K. Human memory CD4+ T cell immune responses against giardia lamblia. Clin Vaccine Immunol. 2016;23(1):11-8.

\section{Submit your next manuscript to BioMed Central and we will help you at every step:}

- We accept pre-submission inquiries

- Our selector tool helps you to find the most relevant journal

- We provide round the clock customer support

- Convenient online submission

- Thorough peer review

- Inclusion in PubMed and all major indexing services

- Maximum visibility for your research

Submit your manuscript at www.biomedcentral.com/submit
) Biomed Central 